\title{
Investigation of $\mathrm{SnSbCu}$ coatings, electrodeposited on bronze and copper
}

\author{
A.Kh. Valeeva ${ }^{\dagger}$, I.Sh. Valeev \\ †valeevs@mail.ru \\ Institute for metals superplasticity problems RAS, Khalturina 39, 450001, Ufa, Russia
}

\begin{abstract}
The soft white anti-friction alloys on tin and lead-based, so-called babbitt metal are widely used bearing materials. The highest operability has multilateral sliding bearings, obtained by casting molten babbitt into the body from a variety of metals and alloys. However, it is known that the fatigue strength of babbitt increases with decreasing thickness so thin layers in many cases may be more effective. One way of obtaining thin layers is electrodeposition. Electrodeposition allows you to manage the process of structure formation and has no negative effects on the substrate. The chemical composition and microstructure of the coatings representing ternary alloy $\mathrm{SnSbCu}$ were examined using scanning electron microscopy (SEM) and X-ray diffraction (XRD). These coatings were prepared in the process of electrodeposition on a copper and bronze substrate. Wear was determined by weight loss in the boundary lubrication regime. The wear intensity was calculated by differentiating the curves of weight loss $(d G / d L)$. It was established that uniform coating of the dark colored needles forms on copper and bronze substrate, presents a solid solution of antimony and copper in the tin, in which are uniformly distributed large bright crystals of $\mathrm{Sn}_{3} \mathrm{Sb}_{2}$ (up to $1 \mathrm{~mm}$ ) compound. X-ray analysis also showed that in the studied surfaces present the same phase $\left(\mathrm{Sn}_{3} \mathrm{Sb}_{2}\right.$, $\mathrm{Cu}_{6} \mathrm{Sn}_{5}$ ), as in the most widely used alloy babbitt $\mathrm{B} 83(\mathrm{Sn} 11 \mathrm{Sb} 5.5 \mathrm{Cu})$. Wear test showed that the obtained coatings significantly reduce the wear intensity of copper and bronze, as at the running-in stage and at the stage of steady wear.
\end{abstract}

Keywords: babbitt, bearings, microstructure, electrodeposition, wear.

\section{Исследование покрытий $\mathrm{SnSbCu,} \mathrm{электроосажденных} \mathrm{на}$ бронзу и медь}

\author{
Валеева А.Х. ${ }^{\dagger}$ Валеев И.Ш. \\ †valeevs@mail.ru
}

Институт проблем сверхпластичности металлов РАН, ул. Халтурина 39, 450001, Уфа, Россия

\begin{abstract}
Широко используемыми подшипниковыми материалами являются мягкие белые антифрикционные сплавы на оловянной и свинцовой основах, так называемые баббиты. Наиболее высокой работоспособностью обладают многослойные подшипники скольжения, полученные заливкой расплавленного баббита в корпус из различных металлов и сплавов. Однако известно, что усталостная прочность баббита повышается с уменьшением его толщины, поэтому тонкие слои во многих случаях могут быть более эффективны. Одним из способов получения тонких слоев является электроосаждение. Электроосаждение позволяет управлять процессом структурообразования и не оказывает негативного воздействия на подложку. С помощью растровой электронной микроскопии (РЭМ) и рентгеноструктурного анализа (РСА) исследовали микроструктуру и химический состав покрытий, представляющих собой тройной сплав $\mathrm{SnSbCu.} \mathrm{Указанные} \mathrm{покрытия} \mathrm{получали} \mathrm{в} \mathrm{процессе} \mathrm{электроосаждения} \mathrm{на} \mathrm{медную} \mathrm{и} \mathrm{бронзовую} \mathrm{подложки.} \mathrm{Износ}$ определяли по потере массы при трении в режиме граничного трения. Интенсивность массового изнашивания рассчитывали дифференцированием кривых потери массы $(d G / d L)$. Установлено, что при электроосаждении на медную и бронзовую подложку образуется сплошное однородное покрытие из игольчатых кристаллов темного цвета, представляющее собой твердый раствор сурьмы и меди в олове, в котором равномерно распределены более крупные светлые кристаллы соединения $\mathrm{Sn}_{3} \mathrm{Sb}_{2}$ (размером до 1мкм). Рентгеноструктурный анализ также показал, что в исследуемых покрытиях присутствуют те же фазы $\left(\mathrm{Sn}_{3} \mathrm{Sb}_{2}, \mathrm{Cu}_{6} \mathrm{Sn}_{5}\right)$, что и в наиболее часто применяющемся сплаве баббит Б83 (Sn11Sb5.5Cu). Испытания на износ показали, что полученные покрытия значительно снижают интенсивность массового изнашивания меди и бронзы, как на стадии приработки, так и на стадии устойчивого износа.
\end{abstract}

Ключевые слова: баббит, подшипники, электроосаждение, микроструктура, износ. 


\section{1. Введение}

Работоспособность подшипников скольжения в значительной степени определяется материалом вкладышей. Наиболее давними подшипниковыми материалами являются мягкие белые антифрикционные сплавы на оловянной и свинцовой основах, так называемые баббиты. Отличительными особенностями всех баббитов являются: хорошая прирабатываемость, способность «поглощать» твердые частицы, отсутствие схватывания со сталью. К их недостаткам относятся низкие механические свойства при температурах выше $100^{\circ} \mathrm{C}$, низкая теплопроводность, сравнительно малая усталостная прочность [1]. Баббиты применяются в подшипниках в виде слоя, полученного специальным процессом заливки в корпус из меди, бронзы, латуни, стали или чугуна [2]. Известно, что усталостная прочность баббитового слоя повышается с уменьшением его толщины, так у вкладышей некоторых современных автомобильных двигателей она составляет 100 мкм и меньше.

Одним из способов получения такого тонкого баббитового слоя, является электроосаждение тройного сплава, близкого по составу к оловянному баббиту [3-8]. Электроосаждение позволяет получить мелкозернистую структуру и управлять процессом структурообразования, кроме того, при его применении не нарушается структура и свойства подложки.

Целью работы является исследование электроосажденных на медную и бронзовую подложки покрытий, представляющих собой тройной сплав $\mathrm{SnSbCu}$, близких по составу к оловянным баббитам.

\section{2. Материалы и методики}

Для электроосаждения тройного сплава $\mathrm{SnSbCu}$ использовали электролит следующего состава: $\mathrm{SnSO}_{4} 0,09 \mathrm{M}$, $\mathrm{CuSO}_{4}$ 0,024M, $\mathrm{H}_{2} \mathrm{SO}_{4}$ 1,9M, формалин (40\%-ный раствор) 0,2М, глицин 0,5М, ОП-10 2 г, 1,4-бутиндиол $20 \mathrm{мл,} \mathrm{SbCl}_{3} 0,01 \mathrm{M}[3]$.

Электроосаждение проводили при плотности катодного тока 0,31 мА/мм², в течение 600 секунд. Покрытие наносили на подложку из меди М1 и бронзы БрОЦС. Использовали инертный анод из графита.

Выбор состава электролита и режима электроосаждения обусловлены проведенными ранее исследованиями [6,7], в которых установлено, что микроструктура и химический состав сплавов в значительной степени зависит от наличия ПАВ и концентрации хлорида сурьмы в электролите (менее $0,0125 \mathrm{M}$ ), обеспечивающих образование сплава с более мелкозернистой структурой (при плотности катодного тока $0,31 \mathrm{~mA} / \mathrm{MM}^{2}$ ), являющегося твердым раствором олова с интерметаллидными фазами $\mathrm{Sn}_{3} \mathrm{Sb}_{2}$ и $\mathrm{Cu}_{6} \mathrm{Sn}_{5}$, присутствующими и в литых баббитах.

Анализ химического состава (соотношения компонентов) и исследование микроструктуры полученных покрытий проводили на растровом электронном микроскопе (PЭM) VEGA3 TESCAN.

Рентгеноструктурный анализ (РСA) проводили на рентгеновском дифрактометре ДРОН 4-07, используя $\mathrm{CuK} \alpha$ излучение с фокусировкой по Брегу-Брентано со щелями Солера на первичном и дифрагированном пучках и графитовым кристалл-монохроматором на дифрагированном пучке.

Износ определяли по потере массы образца в результате трения. Образцы одинаковой площади и радиусом рабочей поверхности 25 мм, предварительно притирали к контртелу - диску на машине трения СМЦ-2 по схеме «диск-колодка». Диск, диаметром 50 мм и шириной 12 мм, выполнен из стали 40Х. Частота вращения диска при испытаниях на износ составляла 300 об/мин. Нагрузка на образец при испытаниях на износ составляла $P=321,7 \mathrm{H}$, что соответствовало значениям давления на площади контакта $p=5,3$ МПа. По результатам предварительных испытаний определены: путь трения до взвешивания $L_{n p(i)}=31,4$ м; путь трения на установившейся стадии износа $L=1000$ м. Интенсивность массового изнашивания определяли дифференцированием кривых потери массы $(d G / d L)$. Исследовали образцы без покрытия и с покрытием, нанесенным по выше описанной методике.

Износ осуществляли в режиме граничного трения при смазывании диска компрессорным маслом КС-19 перед каждым испытанием. Взвешивание образцов осуществляли на аналитических весах ALC210d4.

\section{3. Результаты и обсуждение}

Общий химический состав и масса покрытий, приведены в таблице 1 .

В результате процесса электроосаждения как на медной, так и на бронзовой подложках образуется покрытие, состоящее на 78,0 и 75,4 \% из олова, соответственно. Микроструктура полученных покрытий приведена на рис. 1.

Судя по электронным фотографиям, как на медной, так и на бронзовой подложке, образуется сплошное однородное покрытие из кристаллов темного цвета (рис. 1a, б). По локальному химическому составу (РЭМ) данные покрытия представляют собой твердый раствор сурьмы и меди в олове, в котором равномерно распределены более крупные светлые кристаллы соединения $\mathrm{Sn}_{3} \mathrm{Sb}_{2}$ (размером до 1мкм).

Как известно [9], зависимость между составом сплава типа механической смеси и концентрацией компонентов металлов в электролите определяется уравнением:

$$
\lg \frac{\left[m_{1}\right]}{\left[m_{2}\right]}=A+\frac{z_{2}}{z_{1}} B \lg \left[\frac{m_{1}^{z_{1}^{+}}}{m_{2}^{z_{2}^{+}}}\right]
$$

Табл. 1. Общий химический состав покрытий.

Table 1. The total chemical composition of the coatings.

\begin{tabular}{|c|c|c|c|c|}
\hline \multirow{2}{*}{$\begin{array}{c}\text { Подложка } \\
\text { Substrate }\end{array}$} & \multicolumn{2}{|c|}{$\begin{array}{c}\text { Содержание элемента, \% масс. } \\
\text { The element content, \% mass. }\end{array}$} & \multirow{2}{*}{$\begin{array}{c}\text { Macca, мг } \\
\text { Weight, mg }\end{array}$} \\
\cline { 2 - 4 } & $\mathrm{Sn}$ & $\mathrm{Sb}$ & $\mathrm{Cu}$ & \\
\hline $\begin{array}{c}\text { Медь } \\
\text { Сорper }\end{array}$ & 78,0 & 9,7 & 12,3 & 14,5 \\
\hline $\begin{array}{c}\text { Бронза } \\
\text { Bronze }\end{array}$ & 75,4 & 5,5 & 19,1 & 11,3 \\
\hline
\end{tabular}


где $\left[m_{1}\right],\left[m_{2}\right]$ - массовые проценты компонентов в сплаве; $\left[m_{1}^{z_{1}^{+}}\right],\left[m_{2}^{z_{2}^{+}}\right]-$концентрации компонентов в электролите; $z_{1}, z_{2}$ - заряды катионов; $A$ и $B-$ константы. Согласно этому уравнению, при постоянной плотности тока между логарифмом отношения содержания металлов в сплаве типа механической смеси и логарифмом отношения их катионов в электролите должна существовать линейная зависимость.

На рис. 2 приведены зависимости $\lg [\mathrm{Sn}] /[\mathrm{Sb}]-$ $\lg \left[\mathrm{Sn}^{2+}\right] /\left[\mathrm{Sb}^{3+}\right]$ и $\lg [\mathrm{Cu}] /[\mathrm{Sb}]-\lg \left[\mathrm{Cu}^{2+}\right] /\left[\mathrm{Sb}^{3+}\right]$ для исследуемых сплавов $\mathrm{SnSbCu}$ на медной и бронзовой подложках.

Указанные зависимости (рис. 2 a, b), имеющие нели- нейный вид, позволяют заключить, что при электроосаждении образуются интерметаллиды и твердые растворы. Согласно фазовой диаграмме для тройной системы $\mathrm{SnSbCu,} \mathrm{полученной} \mathrm{авторами} \mathrm{работы} \mathrm{[10],} \mathrm{образует-}$ ся твердый раствор олова, содержащий фазы $\mathrm{Cu}_{6} \mathrm{Sn}_{5}$ и $\mathrm{Sn}_{3} \mathrm{Sb}_{2}$. Это предположение, подтверждается РСА (рис.3), который показал, что в исследуемых покрытиях присутствуют те же фазы $\left(\mathrm{Sn}_{3} \mathrm{Sb}_{2}, \mathrm{Cu}_{6} \mathrm{Sn}_{5}\right)$, что и в сплаве баббита Б83 (Sn11Sb5.5Cu).

Кривые износа бронзового и медного образцов с покрытием и без представлены на рис.4.

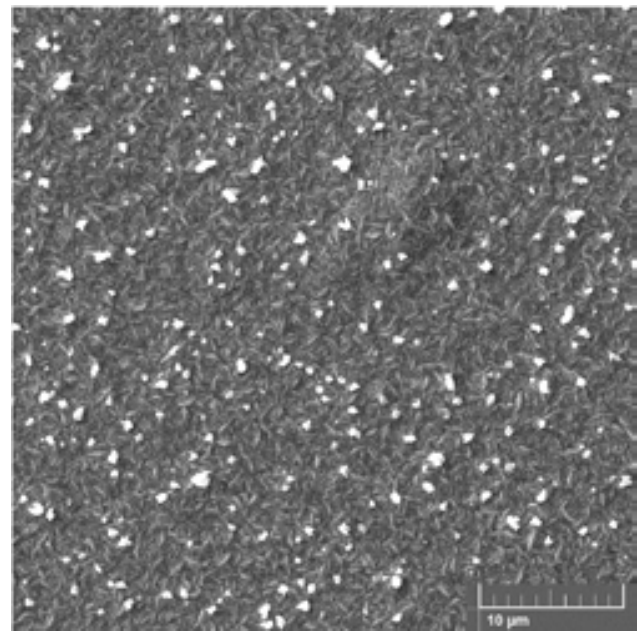

a

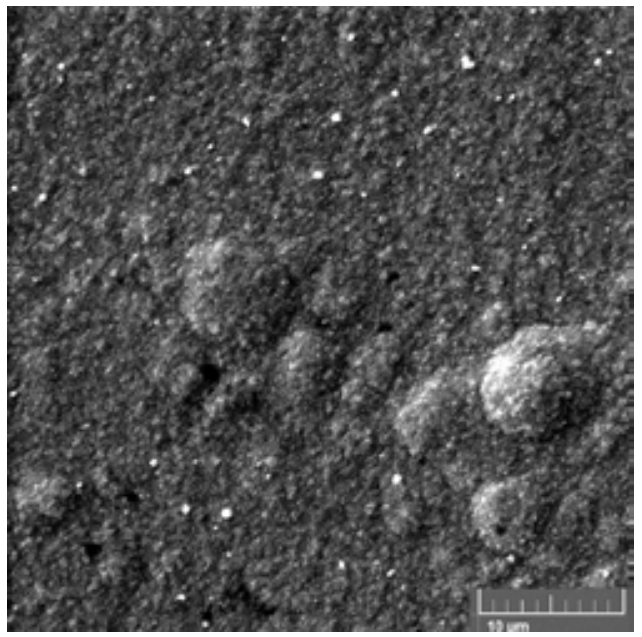

$\mathrm{b}$

Рис. 1. Микроструктура покрытий на (a) медной (b) бронзовой подложке.

Fig. 1. The microstructure of the coatings on the (a) copper, (b) bronze substrate.
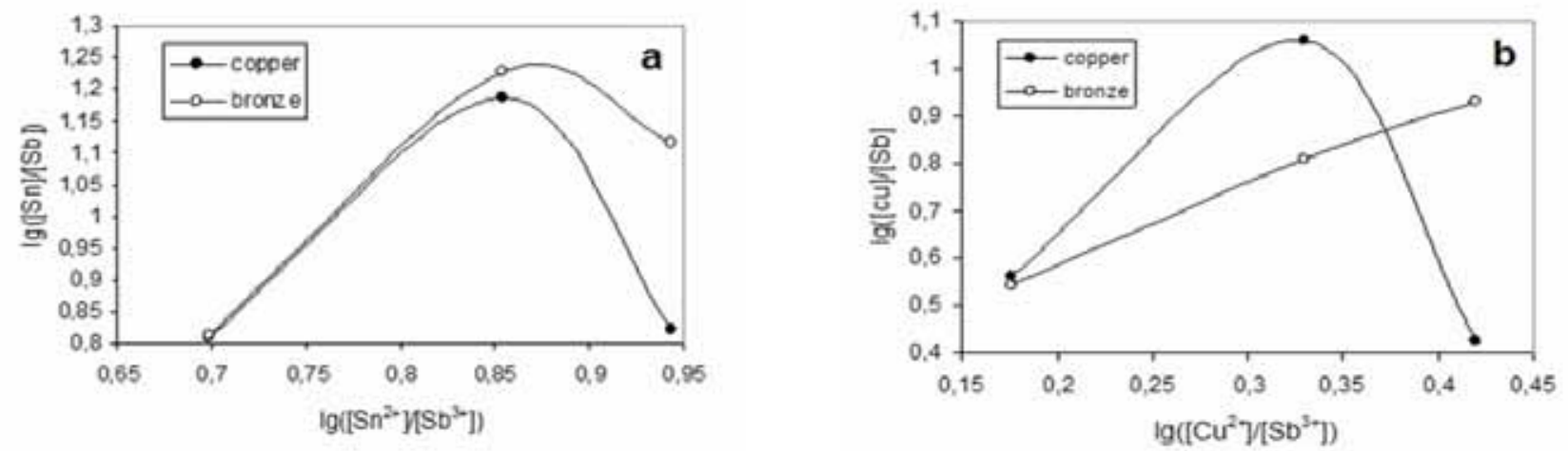

Рис. 2. Зависимости $\lg [\mathrm{Sn}] /[\mathrm{Sb}]-\lg \left[\mathrm{Sn}^{2+}\right] /\left[\mathrm{Sb}^{3+}\right]$ и $\lg [\mathrm{Cu}] /[\mathrm{Sb}]-\lg \left[\mathrm{Cu}^{2+}\right] /\left[\mathrm{Sb}^{3+}\right]$ для сплавов $\mathrm{SnSbCu}$.

Fig. 2. Dependings $\lg [\mathrm{Sn}] /[\mathrm{Sb}]-\lg \left[\mathrm{Sn}^{2+}\right] /\left[\mathrm{Sb}^{3+}\right]$ and $\lg [\mathrm{Cu}] /[\mathrm{Sb}]-\lg \left[\mathrm{Cu}^{2+}\right] /\left[\mathrm{Sb}^{3+}\right]$ for alloys $\mathrm{SnSbCu}$.

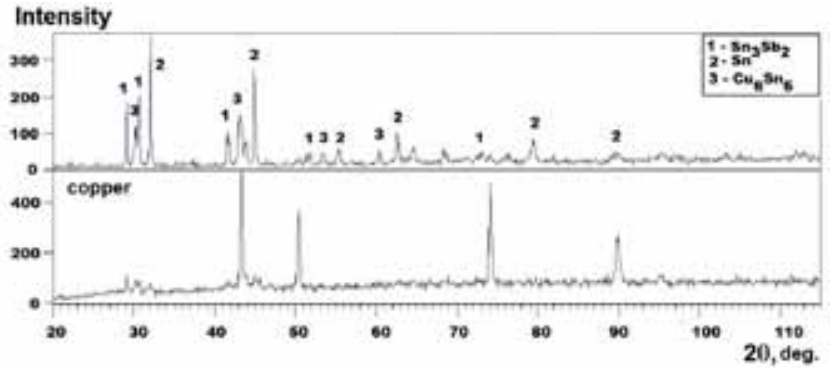

a

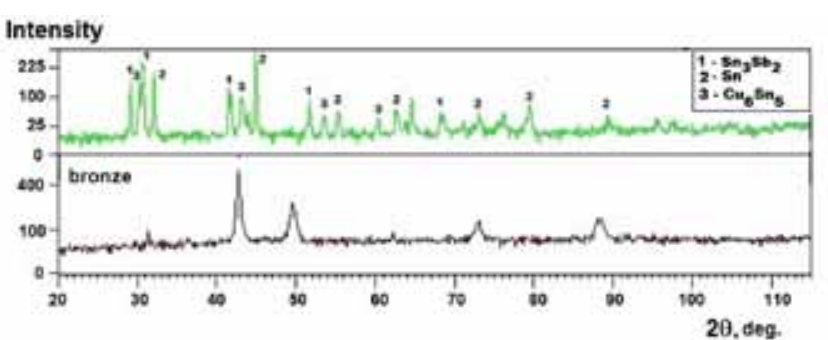

b

Puc. 3. (Color online) Дифрактограмма покрытий, полученных на (а)медной, (b) бронзовой подложке.

Fig. 3. (Color online) The X-ray diffraction diagrams of the coatings obtained on (a) the copper, (b) the bronze substrate. 


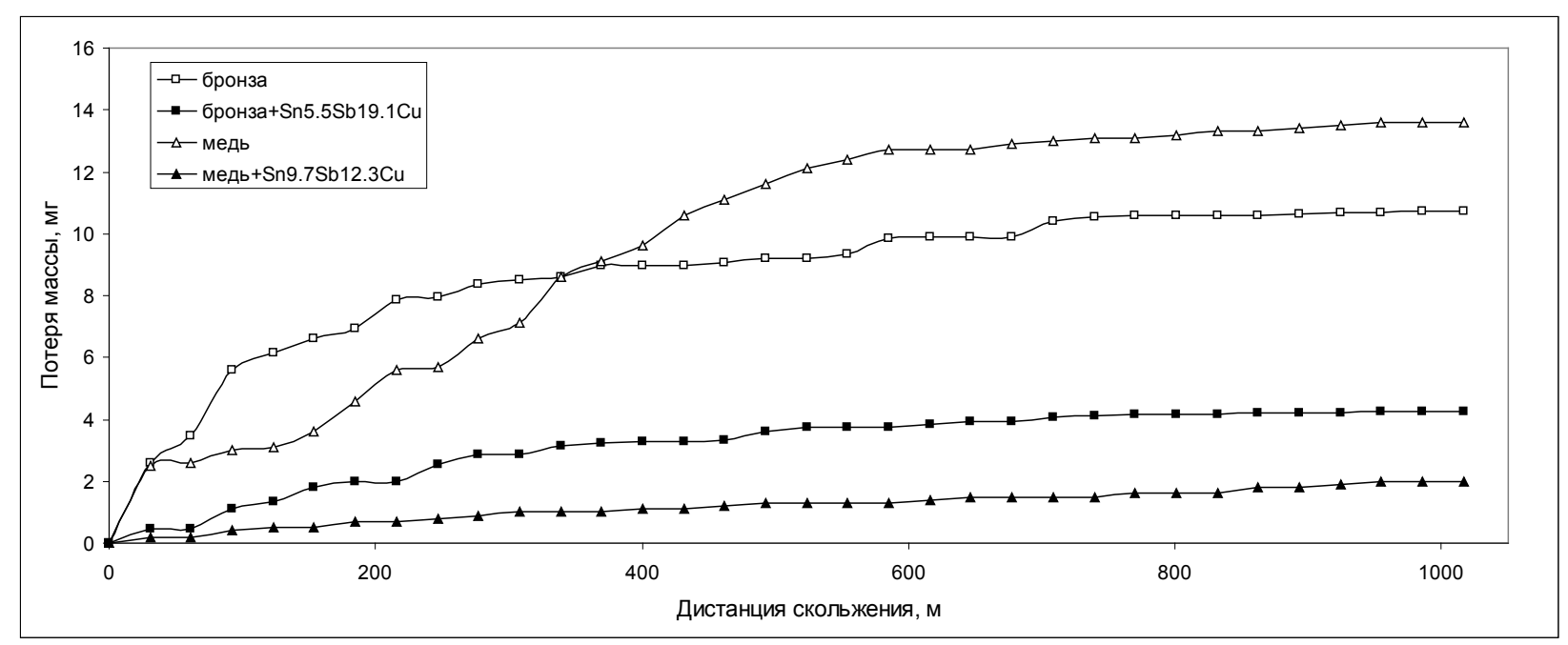

Рис. 4. Кривые износа бронзы и меди с покрытием и без.

Fig. 4. Wear curves of bronze and copper uncoated and with coats.

Зависимости износа медного и бронзового образцов имеют четко выделяемые две стадии (рис.4). На первой стадии - стадии приработки (до 500 м) интенсивность массового изнашивания меди составляет 0,0235 мг/м, бронзы - 0,0187 мг/м. На стадии установившегося износа интенсивность массового изнашивания меди составляет 0,0038 мг/м, бронзы - 0,0030 мг/м. Для образцов с покрытиями стадия приработки на кривой так ярко не выделяется. Интенсивность массового изнашивания на дистанции до 500 м значительно снижается и составляет 0,0026 мг/мдля медного образца с покрытием, и 0,0073 мг/м для бронзового образца с покрытием. Интенсивность массового изнашивания образцов с покрытием на дистанции выше 500 м становится одинаковой и составляет $0,0013 \mathrm{Mг} / \mathrm{M}$.

\section{4. Заключение}

1. Методами растровой электронной микроскопии и рентгеноструктурного анализа установлено, что при электроосаждении на медной и бронзовой подложке образуются покрытия, представляющие собой твердый раствор олова, содержащие фазы $\mathrm{Cu}_{6} \mathrm{Sn}_{5}$ и $\mathrm{Sn}_{3} \mathrm{Sb}_{2}$, по составу близкие к оловянному баббиту Б83 (Sn11Sb5.5Cu).

2. Полученные покрытия в 8-10 раз снижают интенсивность массового изнашивания меди и бронзы на стадии приработки, а на стадии устойчивого износа наблюдается снижение интенсивности массового изнашивания в 3 раза.

\section{Литература/References}

1. Khrushev M.M., Kuritsyna A.D. Friction and wear in machines. M-L.: AS USSR. 1950 (5). 76-82. (in Russian) [Хрущев М.M., Курицына А.Д. Трение и износ в машинах. 1950 (5) 76-82]
2. Garkunov D.N. Tribotechnik. M.: Mashinostroenie. 1999. 336. (in Russian). [Гаркунов Д.Н. Триботехника. М.: Машиностроение. 1999. 336.]

3. G.I. Medvedev, N.A. Makrushin Russian Journal of Applied Chemistry. 74 (2001) 1400-1402. [Г.И.Медведев, Н.А. Макрушин. Журнал прикладной химии. 74 (2001) 1362-1364.]

4. A.Kh. Valeeva, I.Sh. Valeev, R.F. Fazlyakhmetov, N.P. Barykin, A.V. Reva Journal of Friction and Wear. 33 (2012) 34-38. [Валеева А. Х., Валеев И. Ш., Фазлыахметов Р. Ф., Н.П.Барыкин, А.В. Рева. Трение и износ 33 (2012) 46-51.]

5. A.Kh. Valeeva, I.Sh. Valeev, R.F. Fazlyakhmetov, and A.I. Pshenichnyuk. The Physics of Metals and Metallography. 116 (2015) 509-511. [Валеева А. Х., Валеев И. Ш., Фазлыахметов Р. Ф., Пшеничнюк А. И. ФММ. 116 (2015) 538-540.]

6. A.Kh. Valeeva and I.Sh. Valeev. Russian Physics Journal. 58 (6) 2015. 869-872. [А. Х.Валеева, И. Ш. Валеев. Известия ВУЗов. Физика. 6 2015. 121-124.]

7. A.Kh. Valeeva, I.Sh. Valeev. Physics and chemistry of materials treatment. 6 (2015) 24-29 (in Russian) [А.Х.Валеева, И.Ш.Валеев. ФХОМ 6 (2015) 24-29.]

8. A.Kh. Valeeva, I. Sh. Valeev, R.F. Fazlyakhmetov. Letters on Materials 4 (2014) 134-136 (in Russian) [А.Х.Валеева, И.Ш.Валеев, Р.Ф. Фазлыахметов. Письма о материалах 4 (2014) 134-136.]

9. Fedot'yev N.P., Bibikov N.N., Vyacheslavov P.M., Grilikhes S.Ya. Electrolytical alloys. M. Mashgiz (1962) 312.(in Russian) [Федотьев Н.П., Бибиков Н.Н., Вячеславов П.М., Грилихес С.Я. Электролитические сплавы. М.: Машгиз (1962) 312.]

10. Sinn-wen Chen, An-ren Zi, Wojciech Gierlotka, Chingfeng Yang, Chao-hong Wang Shih-kang Lin, Chia-ming Hsu. Mat. Chem. and Phys. 132 (2012) 703-715. 